\title{
Improving Mentoring in Higher Education in Undergraduate Education and Exploring Implications for Online Learning
}

\section{Mejorando la mentoría en la educación universitaria y explorando las implicaciones para el aprendizaje en línea}

\author{
Camey L. Andersen \\ Brigham Young University. Provo, USA \\ camey.andersen@gmail.com \\ Richard E. West \\ Brigham Young University. Provo, USA \\ rickwest@byu.edu
}

\begin{abstract}
This article is a literature review of mentoring and higher education academic literature from 2008-2018. The review analyzed what makes an effective mentor and what are the implications of practice for those strategies. This article is for higher education leaders, mentoring programs, and mentors who want to improve their traditional and online mentoring programs and mentoring practices. After narrowing the search terms, the researcher searched EBSCO and ERIC databases and this search produced a combined total of 256 results. These articles were further narrowed to 34 articles that met the keyword search and exclusion criteria. The remaining articles are the focus of the literature review analysis for mentoring and higher education literature. The review produced three major themes of impact of mentoring, role of mentor, and mentoring programs, as well as implications for practice for each theme. The researcher further examined the themes in detail and provided information about retention, persistence, long-term benefits of mentoring, student interaction, student support, role models, types of mentoring programs, platforms for mentoring, and mentor training. The review concludes with suggestions for further research, including recommendations for mentor training and online mentoring.

Keywords: higher education, mentor, online education, retention, role model, training; la tutoria, educación superior, entrenamiento de mentores, roles de mentor, mentoría en línea, educación a distancia, aprender en línea, programas de mentoría, retención, persistencia
\end{abstract}

\section{Introduction}

There is a greater awareness of the emotional needs of today's higher education students as universities seek to increase student retention and persistence and minimize attrition. Mentoring supports students in their academic and emotional well-being as they work towards their educational goals. Providing student access to quality mentors is regarded as a responsibility of higher education institutions. Ragins and Kram (2007) described the impact of such effective mentoring: "At its best, mentoring can be a life-altering relationship that inspires mutual growth, learning, and development. Its effects can be remarkable, profound, and enduring; mentoring relationships have the capacity to transform individuals, groups, organizations, and communities" (p. 3).

The potential for transformative growth in individuals is one of the defining characteristics of mentoring and one reason it is a valuable field of study today. In addition, mentoring has been

RED. Revista de Educación a Distancia. Núm. 64, Vol. 20. Artíc. 2, 30-09-2020

DOI: http://dx.doi.org/10.6018/red.408671 
shown to have long-lasting benefits for students for up to two years after mentoring has ended (Bettinger \& Baker, 2014). Education is changing rapidly and the way students learn is changing with it. Online learning is going to be a permanent part of the 21 st century, but online learning can be isolating for students (Dumford \& Miller, 2018; Gillett-Swan 2017) and it requires new skills that many students don't have, like self-regulation (Bradley, Browne, \& Kelley, 2017; Wandler \& Imbriale, 2017). Thus, students are not prepared for online learning. However, mentoring can help, and has been shown to help students in many ways to better acclimate to college.

This article is for higher education leaders, mentoring programs, and mentors who want to improve their mentoring program and practices. In this literature review we first frame the general mentoring context and field of mentoring in higher education. Then we review the latest findings from the literature (2008-2018) about the role of mentoring for undergraduate education and implications for practice. We then conclude with future implications for mentoring research in higher education and online learning.

\section{What is Mentoring in Higher Education?}

Mentoring can have multiple purposes and objectives and can be achieved through various methods (Hobson, Ashby, Malderez, \& Tomlinson, 2009). A mentoring definition by Lev, Kolassa, and Bakken (2010) clarifies the approach used for evaluating mentoring literature in this literature review, "Mentoring occurs when a senior person or mentor provides information, advice, and emotional support to a junior person or student over a period of time" (p. 1). Definitions for mentoring often depend on the field of literature being cited. In higher education, one of the most descriptive assessments of mentoring is provided by Shandley (1989):

First, it is an intentional process of interaction between at least two individuals .... Second, mentoring is a nurturing process that fosters the growth and development of the protégé .. .. Third, mentoring is an insightful process in which the wisdom of the mentor is acquired and applied by the protege .... Fourth, mentoring is a supportive, often protective process. The mentor can serve as an important guide or reality checker in introducing the protege to the environment he or she is preparing for. Finally ... an essential component of serving as a mentor is role modeling. (as cited in Jacobi, 1991, p. 507).

Mentoring is a process, not an event. The Council of Graduate Schools provided additional insight into how these mentors assist students, using a definition by Zelditch (1990):

Mentors are advisors, people with career experience willing to share their knowledge; supporters, people who give emotional and moral encouragement; tutors, people who give specific feedback on one's performance; masters, in the sense of employers to whom one is apprenticed; sponsors, sources of information about and aid in obtaining opportunities; models, of identity, of the kind of person one should be to be an academic. (as cited in Gaffney, 1995, p. 1)

Mentors fill many roles and their ultimate success depends on how those roles are understood and applied in a mentoring program and more importantly, by mentors in the lives of individual students.

Nora and Crisp (2007) further expanded these definitions to better explain the depth of support mentors can provide to students:

Improving Mentoring in Higher Education in Undergraduate Education and Exploring Implications for Online Learning. Camey L. Andersen y Richard E. West.

Página 2 de 25 
[Mentoring] must include a sense of a support system provided by the mentor and ... this support system focuses on creating an emotional safety net as well as a psychological perspective. Students perceived that words of encouragement and support provided a sense of attentiveness and nurturing that encompassed a mentoring experience. Undergraduates also perceived mentoring involved a sense of exploration and focus on goal setting. (p. 350)

To be successful, both mentoring participants need to show trust and respect for each other, understand expectations, be committed to the partnership, and interact regularly (Bierema \& Merriam, 2002). Sponsoring organizations also need to support the mentoring relationship, its process, and ongoing training.

\section{Theoretical Approaches}

Theoretical approaches to mentoring have traditionally been more focused on different characteristics of mentoring than on all-inclusive theories or approaches (Jacobi, 1991). There were three significant reviews of undergraduate mentoring programs from 1991-2012 (Crisp \& Cruz, 2009; Gershenfeld, 2014; Jacobi, 1991). In over 20 years of research, use of theoretical foundations for studies have increased in the literature, and $70 \%$ of undergraduate mentoring program articles in the latest literature review (2008-2012) cited a theoretical framework (Gershenfeld, 2014). While some mentoring studies cited classic theories as a foundation for mentoring such as Bandura's (1977) social learning theory or Vygotsky's (1978) zone of proximal development, these principles or other classic theories cannot fully explain the many dimensions of mentoring (Jacobi, 1991; Kramer-Simpson, 2018; Renn, Steinbauer, Taylor, \& Detwiler, 2014).

Without a classic theoretical foundation, mentoring studies often refer to established or original mentoring frameworks. These mentoring models are the foundation for structured mentoring programs in determining academic achievement (Jacobi, 1991). Jacobi (1991) cited four categories of mentoring frameworks: "(a) involvement in learning, (b) academic and social integration, (c) social support, and (d) developmental support" (pp. 523-525). What is the mentor's role in each of these frameworks? For "involvement in learning," the mentor recommends that the student identify ways to increase their learning and suggests specific ways that learning could be applied (e.g., internship) (Jacobi, 1991). The mentor role in "academic and social integration" is to consider student behavior with the perspective of student feelings and combine these concepts to determine mentoring outcomes. For "social support," mentors provide different types of support to students to improve their learning experience, including emotional and knowledge support, and this support helps students manage stress in their college experience. Mentors facilitate "developmental support" for students as they help them go beyond information sharing to improving skills in mentoring areas such as study skills or persistence.

These frameworks need to be considered in relation to how mentoring interfaces with academic achievement. Tinto's $(1975,1993)$ social integration theory is the most often cited theory in undergraduate mentoring studies in the Gershenfeld (2014) review. This theory suggested that as students are assimilated into the campus environment, they are more likely to be persistent in their academic studies and ultimately graduate from the university. Other theories cited in the Gershenfeld (2014) review represented a range of outcomes from social networks to social supports to methods of learning. Because mentoring studies have so many differences in focus, from better understanding student mentoring benefits (Baier, Markman, \& Pernice-Duca, 2016;

Improving Mentoring in Higher Education in Undergraduate Education and Exploring Implications for Online Learning. Camey L. Andersen y Richard E. West.

Página 3 de 25 
Hu \& Ma, 2010; Liu, Xu, \& Weitz, 2011) to mentor quality assessment (Bowser, Hux, McBride, Nichols, \& Nichols, 2014; Shaffer, Zalewski, \& Leveille, 2010) to how mentoring is affected by demographic and cultural issues (Castellanos, Gloria, Besson, \& Harvey, 2016; Cox, Yang, \& Dicke-Bohmann, 2014; Villaseñor, Reyes, \& Muñoz, 2013) they are unlikely to be unified in a theoretical position in the near future.

Another theoretical framework are the following mentoring domains cited by Nora and Crisp (2007):

1. Psychological or emotional support

2. Support for setting goals and choosing a career path

3. Academic subject knowledge support aimed at advancing a student's knowledge relevant to their chosen field

4. Specification of a role model (p. 342)

These mentoring domains were further examined in literature reviews by Crisp and Cruz (2009) and Gershenfeld (2014). In the studies reviewed by Gershenfeld, it is significant that $60 \%$ had mentors who acted in multiple roles for student support, showing that mentoring programs can use this framework to better outline mentor responsibilities. Other studies also used this framework to show how mentoring helps students achieve success (Henry, Bruland, \& Sano-Franchini, 2011; $\mathrm{Hu} \& \mathrm{Ma}, 2010)$. For mentoring studies and mentoring programs, selecting a theory is not automatic and required understanding different mentoring frameworks and student dynamics, and then choosing the best approach for the designated mentoring.

Research remains limited on which theoretical approaches are most effective for online mentoring in distance education. Differences in online-only and blended mentoring programs will impact the theoretical approach used (Neely, Cotton, \& Neely, 2017). Research has shown that traditional frameworks can be adapted for online use. For example, Hamilton and Scandura (2003) configured four mentoring models - network mentoring, multiple mentoring, team mentoring, and mentoring and learning - to internet-conducive versions that take into account online affordances and constraints (p. 398). These frameworks emphasize how online mentoring must account for mentors and mentees developing an increased ability to manage communication possibilities, removing physical barriers of mentoring to allow the frameworks to be more completely applied, and minimizing racial, demographic and gender inequities by expanding the scope of mentoring influence. Other research has provided potential online frameworks for use, such as Lenear's (2007) Mentor Initiation Model and Protégé Collaboration Model, which reinforced the importance of establishing connection and goal-setting in mentoring relationships and provided recommendations for online mentor/protégé partnerships. However generally, online mentoring theory has been insufficient to keep up with the expanding field of online learning. The available online mentoring research has struggled to show effective online mentoring process and its impact on students (Gravel, 2012; Sanyal \& Rigby, 2017).

\section{Developing Effective Mentors}

In addition to the gaps in the theoretical framework, the path to developing effective mentors remains somewhat elusive. A student's enrollment in a college mentoring program should not automatically equate with the student being mentored (Lunsford, 2011). Mentors need to learn how to mentor effectively or have mentoring skills reinforced through training. Training is often cited as an important requirement for effective mentoring, but the characteristics of those trainings

Improving Mentoring in Higher Education in Undergraduate Education and Exploring Implications for Online Learning. Camey L. Andersen y Richard E. West.

Página 4 de 25 
are often vague (Anderson, Motto, \& Bourdeaux, 2014; Neely et al., 2017). In a review of mentoring programs, Ehrich, Hansford, and Tennent (2004) explained, "Administrators must . . . consider the issue of training, commonly cited in the literature as a key to the success of mentor programs" (p. 535). Who trains the mentors, what training they receive, and how often they receive training, including follow up training, are important aspects of mentor development, but are personalized to individual programs and could be difficult to generalize. Online mentoring may require additional training. Putsche, Storrs, Lewis, \& Haylett, (2008) gave an example of how mentor training was facilitated in one program:

Training sessions were held separately for mentors and mentees, during which the coordinator discussed the purposes of the program; the benefits of mentoring related to psychosocial support, academic and career planning, and student retention and graduation rates; the various roles mentors take (i.e. friend, advocate, advisor, supporter, role model, sponsor, listener, and coach) .... Participants were also asked to express their mentoring expectations through metaphor. (p. 519)

The purpose of this metaphor exercise was to help mentors think about and share their mentoring expectations before beginning a mentoring relationship.

Depending on the students mentored, training may need to incorporate additional cultural, ethnicity, or gender-related training (Jensen, 2017; Putsche et al., 2008). In a 2017 study, a student shared how their mentor had helped them, "[My mentor] has really helped me break down professional barriers and if I'm having a meltdown, I know I can call [my mentor] and [my mentor] is usually pretty good to talk to and has been flexible" (Jensen, 2017, p. 642). While programs may have provided basic mentor training on how to assist students in similar situations, many mentors are left on their own to self-train through the mentor process, learning as they go along.

\section{The Challenges of Mentoring}

For the many benefits of mentoring, there are challenges in addition to training challenges. In higher education, it can be difficult to find and provide mentoring for all students who need mentoring, including identifying available or volunteer mentors and what methods will be most successful in establishing a quality mentoring relationship (Johnson, 2015). How to select the most effective mentor is disputed. Some research showed a higher degree of satisfaction with the mentoring relationship from students who found their own mentors, as opposed to being assigned a mentor (Bear \& Jones, 2017). However, without help from mentoring program matching, students may lack information on how to find a mentor or may be complacent in finding a mentor on their own. Other studies reported that mentoring relationships were more successful when mentors and students were matched based on common perspectives (Allen \& Eby, 2003; Hernandez, Estrada, Woodcock, \& Schultz, 2017).

Mentors need to have specialization in specific educational or professional fields or be of a specific demographic category to provide the best mentorship opportunities for certain groups of students (Poor \& Brown, 2013). Mentors may or may not have a long-term commitment to students or to the mentorship organization. Mentor time or flexibility and availability to meet with mentees may be limited. A 2004 review of more than 300 mentoring articles from the education, business, and medical fields from 1986-2002 showed challenges that are consistent with challenges still being faced in mentoring (Ehrich et al., 2004). The review explained, "The difficulties associated with mentoring were similar for both mentors and mentees .... The two most frequently cited

Improving Mentoring in Higher Education in Undergraduate Education and Exploring Implications for Online Learning. Camey L. Andersen y Richard E. West.

Página 5 de 25 
outcomes were (a) lack of time and (b) professional expertise and/or personality mismatch" (Ehrich et al., 2004, p. 525).

There are many different types of mentoring programs. Formal mentoring programs are generally not standardized in goals and objectives, so it is difficult to categorize them or accurately compare them (Ehrich et al., 2004; Gershenfeld, 2014; Jacobi, 1991; Nora \& Crisp, 2007). Since many mentoring programs assist specialty groups (a certain demographic or particular field), they may also have unique characteristics that are more challenging to generalize to a less-specialized mentoring programs (Butz, Spencer, Thayer-Hart, Cabrera, \& Byars-Winston, 2018; Castellanos et al., 2016; Putsche et al., 2008; Shultz, Colton, \& Colton, 2001). Also, while many mentoring programs are assumed to lead to improved student outcomes, these programs lack evaluations to show how the program works (Ehrich et al., 2004; Gershenfeld, 2014; Jacobi, 1991; Rees Lewis, Easterday, Harburg, Gerber, \& Riesbeck, 2018). In addition, mentoring programs that are not volunteer-based may face funding issues that affect that number of mentors available or how the program functions.

Even the best mentor programs can face challenges from mentee students. Students may not understand what mentor opportunities are available to them (Black \& Taylor, 2018; Ehrich et al., 2004). They may not feel a connection with their mentor, they may prefer a different mentoring style than is offered to them, or they may want more time with the mentor than the mentor has available and consequently become dissatisfied with the relationship. Many mentors are now connecting with students online, instead of, or in addition to in-person contacts, and that interface can create potential challenges with student interaction.

Online mentoring provides benefits to students who may not otherwise have had access to mentors, but it also creates mentoring challenges. Only interacting online can make it more difficult to develop an effective mentoring relationship between mentors and students (Bear \& Jones, 2017; Purcell, 2004). Without face-to-face, in-person communication between mentors and students, the mentor relationship may seem impersonal and other tools may need to be used to keep the mentor/student relationship progressing forward (Purcell, 2004; Rees Lewis, Harburg, Gerber, \& Easterday, 2015; Sanyal \& Rigby, 2017). We use the term in-person, rather than faceto-face, to be more accurate since online synchronous video discussion technically provides some of the benefits of non-verbal communications present in in-person communication. Online mentoring interaction also means it can be difficult to interpret physical gestures and mannerisms which are normal parts of an in-person encounter. Also, effective in-person mentors may struggle with mentoring online (Shrestha, May, Edirisingha, Burke, \& Linsey, 2009). Training, practice, and other accommodations may need to be made to match the quality of in-person mentoring.

Lack of training for mentors and support and evaluation of mentoring programs can also be problematic (Ehrich et al., 2004; Henry et al., 2011). The literature is also limited in perspectives on how to develop effective mentors, leaving us still in need of understanding what makes a successful mentor. We also need to know more about the experience of becoming a mentor and better understand mentor concerns and what best practices will help them better fulfill their roles as mentors and support students, particularly underrepresented and nontraditional students.

\section{Review Question}

Mentoring in higher education is still a developing field where there are many questions to be answered that will strengthen the quality of mentors and improve the student experience with

Improving Mentoring in Higher Education in Undergraduate Education and Exploring Implications for Online Learning. Camey L. Andersen y Richard E. West.

Página 6 de 25 
mentoring. In this literature review, we were guided by the question: What makes an effective mentor in higher education?

\section{Methods}

\section{Search Strategy}

Two databases were searched, ERIC and PsycINFO, to identify articles that examined the effects of mentoring students in higher education environments (see Table 1). Topics for inclusion when selecting articles included "mentoring" and "higher education." Keywords from these topics included "college, adult education, tertiary education, e-learning, distance learning, coach or advisor." Other keywords were used for exclusion terms, including K-12, peer mentoring, graduate mentoring, graduate student mentoring, teacher mentoring, sports coaching, disability research, and specialty fields. Topics for inclusion and exclusion were selected based on the criteria that a senior (nonacademic) mentor provides mentoring support for a junior mentee (undergraduate student) over time (Lev et al., 2010). The search included peer-reviewed journals, but excluded books, reports and dissertations. All searches were limited to English publications and to the timeframe of 2008-2018. This timeframe was examined because the last decade has seen advances in the Internet that affect mentoring practices (Dawson, 2014; Sanyal \& Rigby, 2017; Xu \& Jaggars, 2013). Also, this review updates our understanding or mentoring practices in higher education since Gershenfeld's (2014) literature review.

\section{Study Screening and Data Extraction}

The search process allowed for a review of both databases simultaneously, so any duplicate articles were eliminated in the search. From the search results, a two-part screening further narrowed the search for articles. First, citation titles and abstracts were examined for inclusion keyword matches. Articles that did not meet inclusion keyword criteria of search terms or included exclusionary keyword terms were eliminated from the search. Second, in reviewing the remaining articles, full texts of the articles were read and reviewed based on exclusion criteria. For articles that met both screening requirements, data was excerpted for additional review based on the combined search topics.

\section{Study Selection}

The search provided 256 records. After screening titles and abstracts, 88 eligible full-text articles were evaluated for inclusion search terms ("mentoring" and "higher education" keywords), and those that contained exclusionary terms were eliminated from the search (see Table 1). Fiftyfour articles were ultimately excluded based on additional screening for articles about mentoring and higher education based on the keyword terms from the initial search. We excluded articles that did not meet inclusion keyword criteria, including articles about students who were not undergraduates, or articles about peer mentoring, faculty mentoring of students, graduate student mentoring, graduate student-to-undergraduate student mentoring, and nonstudent mentoring. After this process, 34 articles remained that were examined as part of this analysis.

Improving Mentoring in Higher Education in Undergraduate Education and Exploring Implications for Online Learning. Camey L. Andersen y Richard E. West. 
Table 1

Developing Search Terms

\begin{tabular}{|c|c|c|}
\hline & Subject & Keywords \\
\hline & Mentoring & $\begin{array}{l}\text { "mentor" or ("coach" not "sports") or } \\
\text { "advisor" }\end{array}$ \\
\hline And & Higher Education & $\begin{array}{l}\text { "higher education" or "college } \\
\text { student" or "adult education" or } \\
\text { "tertiary education" or } \\
\text { "postsecondary" or "post secondary" } \\
\text { or "undergraduate" }\end{array}$ \\
\hline Not & $\mathrm{K}-12$ & $\begin{array}{l}\text { "K-12" or "K12" or "primary" or } \\
\text { "secondary" or "children" or } \\
\text { "elementary" or "youth" }\end{array}$ \\
\hline Not & Peer Mentoring & "peer" \\
\hline Not & Graduate Mentoring & graduate or doctoral or postgraduate \\
\hline Not & Graduate Student Mentoring & $\begin{array}{l}\text { "graduate student*" or "doctoral } \\
\text { student*" or "master* student*" or } \\
\text { "postgraduate student*" }\end{array}$ \\
\hline Not & Teacher Mentoring & $\begin{array}{l}\text { faculty or instructor or professor or } \\
\text { "college teacher" or teacher or } \\
\text { principal }\end{array}$ \\
\hline Not & Sports Coaching & $\begin{array}{l}\text { athlete or sport* or athletic* or } \\
\text { "physically active" }\end{array}$ \\
\hline Not & Disability Research & \\
\hline
\end{tabular}

Improving Mentoring in Higher Education in Undergraduate Education and Exploring Implications for Online Learning. Camey L. Andersen y Richard E. West.

Página 8 de 25 
disability or disabilities or disabled or impairment or impaired or special or special needs

Not

Specialty Fields

nursing or medical or veteran

Note. The summary of initial results was: ERIC 156 articles; PsycINFO 100 articles for a total of 256 articles. The articles were further reviewed and narrowed to 34 articles.

We used open coding to conduct our analysis of the articles, beginning without a priori categories. We first read the entire corpus of articles to get a sense for the whole, and then reread each article to determine the main themes or topics discussed in that article. From this list of themes or topics, we identified three that seemed to represent the majority of the articles. We then reread the 34 articles to determine which of the three themes each article discussed (see Table 2).

Table 2

Article Themes

Theme Contributing Articles

Impact of Mentoring (Total articles) 16

Student Retention 7

Student Persistence 8

Long-term Benefits 5

Role of Mentor (Total articles) 25

Student Interaction 7

Student Support 12

Role Models 9

Mentoring Programs (Total articles) 27

Types of Mentoring Programs 10

Mentoring In-person, Online, or Blended 16

Mentoring Training

9

\section{Impact of Mentoring}

While mentoring generally presumes positive effects for the mentored student from the relationship with the mentor, the literature shows that there are tangible benefits that go beyond

Improving Mentoring in Higher Education in Undergraduate Education and Exploring Implications for Online Learning. Camey L. Andersen y Richard E. West.

Página 9 de 25 
the relationship itself. One reason mentoring is so valuable in higher education is the lasting advantages to students who participate in mentoring relationships. Benefits include improved student retention, student persistence, and long-term benefits that reach beyond the college experience.

\section{Student Retention}

One mentoring benefit cited in the literature was student retention. In these review studies, retention was generally increased by student participation in mentoring or in a mentoring program (Allen \& Lester, 2012; Gravel, 2012; Letkiewicz et al., 2014; Poor \& Brown, 2013; Villaseñor et al., 2013), and often significantly improved. Mentoring provided both long-term and short-term retention benefits. One study showed student retention rates of $94 \%$ from students involved in a mentoring program (Poor \& Brown, 2013). Another study found that semester completion retention rates were improved by students' participation in a mentoring program after previous semesters of poor retention without the program (Allen \& Lester, 2012). The most significant lack of retention was in the first two college semesters (freshman year), which has further implications for the importance of encouraging and providing mentoring from the beginning of the college experience. Retention was particularly important for online students, who are more likely to drop out of college than students who attend in-person classes (Gravel, 2012).

Student retention provides significant challenges for mentors. It can be impacted by lack of mentoring opportunities or a mismatch with mentors. Retention could be negatively affected from struggles faced by minority students, and unless the mentoring is effective mentoring, one study showed no impact from mentors for these or any students studied (Schultz et al., 2011). Online students have increased higher education retention challenges and while developmental advising is recommended for these students, mentors may not be aware of the need for specialized attention for them (Gravel, 2012). However, online mentoring can provide opportunities for increased access to a mentor and increased online support availability that can strengthen students. Because the positive relationship between students and mentors has been shown to strongly effect retention outcomes, online programs need to prioritize establishing and maintaining these mentorstudent relationships.

There are also educational obstacles that affect retention such as lack of family support and financial struggles (Letkiewicz et al., 2014; Villaseñor et al., 2013). A study by Baier et al. (2016) showed that dropout rates could be minimized by incorporating mentoring with an approach for student self-efficacy. Mentors can overcome retention difficulties through increased awareness and training.

\section{Student Persistence}

Closely related to retention are mentoring benefits to student persistence. Participation in a field-specific mentoring program can increase student persistence in that program through a semester as well as through the entirety of the college years (Allen \& Lester, 2012; Butz et al., 2018; Hinds \& Shultz, 2018; Poor \& Brown, 2013). As students near the end of their college experience, mentoring has been shown to also help persistence in job searches (Renn et al., 2014). Mentors were able to help empower students with the ability to overcome negative employmentseeking behaviors, such as procrastination, unpredictable job searches, and lack of networking, through support and by providing them with tools to overcome these self-destructive behaviors for

Improving Mentoring in Higher Education in Undergraduate Education and Exploring Implications for Online Learning. Camey L. Andersen y Richard E. West. 
finding a job. One study contradicted the majority of findings on student persistence and mentoring by claiming that student persistence in a given field was not affected by mentoring interaction (Schultz et al., 2011). These results may be more indicative of quality of mentoring instead of the role of the mentor (Hernandez et al., 2017). A more representative study showed that all students with mentor relationships showed increased persistence in college studies, with the probability for persistence associated with student interaction and perceived value of the mentor relationship (Hu \& Ma, 2010). Hu and Ma (2010) further explained the impact of quality mentoring, "The frequency of contact with college mentors does not affect student persistence whereas the extent to which students turn to their mentors for support does" (p. 338). Effective mentors play an important role as cheerleaders for students as they move ahead in their studies.

\section{Long-Term Benefits of Mentoring}

Mentoring benefits have the potential to be long-lasting and impact students beyond their time in higher education. Mentor programs that foster social connections increase their possibility to have long-term impact on students. Programs could encourage and plan alumni interaction that connects students with future opportunities, sponsor online social networks where participation connects students to possible support, and plan activities that engage student spouses or significant others where additional contact and social interaction is created that extended past the mentoring opportunity (Liu et al., 2011; Mondisa \& McComb, 2018). By intentionally establishing online mentoring connections, mentors also create opportunities for their university or organization to contact and potentially benefit from mentee skills in the future as they advance in their career and professional life (Poor \& Brown, 2013).

Mentoring programs also strengthened students' future opportunities by helping them see a vision for their careers and post-college plans (Barbuto, Story, Fritz, \& Schinstock, 2011; Poor \& Brown, 2013; Smith-Ruig, 2014). As student talents and potential are validated by mentors, they are able to envision a successful future in their career beyond their college experience. One mentoring study on engineering students explained how this happens, "The mentoring program may help those students that have the technical capability to be an engineer but are just not sure of their choice. Having a mentor can reinforce the confidence a student already has about her capabilities in engineering" (Poor \& Brown, 2013, p. 426). Effective mentors help students see beyond their college experience to a successful future where what they are doing now has benefitted them.

\section{Implications for Practice}

Mentors can have a lasting effect on students in retention, persistence, and long-term outcomes. Quality mentoring for students impacts how they view the sponsoring organization or the mentor's career field (Liu et al., 2011). With this understanding, mentors can frame mentoring experiences to emphasize retention and persistence at the university or possibilities in a job field and provide encouragement for students to achieve their own ambitions in those areas.

Recognizing that undergraduate mentoring relationships tend to be shorter than graduate school or professional mentoring relationships, mentors should aim for quality rather than quantity mentoring interactions (Hernandez et al., 2017). Mentors can recognize that they do not have to make a significant time commitment to make a difference for students if they will invest in the quality of the mentoring relationship (Poor \& Brown, 2013). Mentors can further extend the

Improving Mentoring in Higher Education in Undergraduate Education and Exploring Implications for Online Learning. Camey L. Andersen y Richard E. West.

Página 11 de 25 
benefits of mentoring by emphasizing the social community and promoting connections in the mentoring relationship and helping students find others who can also offer support (Mondisa \& McComb, 2018). Effective mentors look to broaden the scope of mentoring.

\section{Role of Mentor}

The role of mentor and how it is applied was another most frequently cited mentoring characteristic in this literature review. A mentor's responsibilities and impact or lack of impact on students is shaped by a variety of factors, including mentoring program objectives and constraints, how he or she defines her role, mentor knowledge or expertise, the amount of time spent mentoring a student and for what duration, perceived quality of mentorship, and how a mentor connects with student mentoring goals (Bear \& Jones, 2017; Bowser et al., 2014; Hernandez et al., 2017; KramerSimpson, 2018). Healy, Lancaster, Liddell, and Stewart (2012) argued that mentors do not need to know everything or answer all student questions. Instead, the mentor's objective should be to help students discover the most effective learning path and have a meaningful university experience, guided by a trusted advisor. While expertise in an area can strengthen mentoring capabilities, for some students their mentor's professional skill was not as critical as their commitment to mentoring and helping the student to achieve their academic and professional goals (KramerSimpson, 2018; Luckett \& Luckett, 2009). The literature showed three main areas of focus for the role of mentor: student interaction, student support, and the mentor as a role model.

\section{Student Interaction}

How a mentor interacts with their mentee student is fundamental to the mentorship relationship. Interaction may be prescriptive, where the mentor provides help in specific areas or developmental, where advice on a broader spectrum of topics is offered (Anderson et al., 2014; Braun \& Zolfagharian, 2016; Kramer-Simpson, 2018; Rees Lewis et al., 2018). Kramer-Simpson (2018) explained how a personalized mentoring interaction can empower students, "Students were given tasks that they felt very independent in completing, but were closely monitored, albeit unobtrusively. Most importantly, these industry mentors gave [students] the opportunities to learn, and even make mistakes in the course of making decisions" (p. 92). In the most effective student interactions, mentors offered ongoing suggestions or assignments, provided corrective help as needed, and assisted the student in staying focused on and meeting their goals.

Mentor contact and frequency of interaction is another important element of the mentor student interaction. In one study, student registration improved with advisor contact, and if the student received email and phone contact, their registration was greater than with only one contact (McClure, 2017). The frequency of mentoring contact as the mentoring relationship developed and evolved may also reflect the quality or design of the mentoring relationship (Braun \& Zolfagharian, 2016; Sanyal \& Rigby, 2017). As the mentoring relationship matured, the specific number of interactions may be less important than the quality of the interaction (Hu \& Ma, 2010).

As online and traditional programs consider what instruments are most effective in tracking mentoring relationship efficacy, $\mathrm{Hu} \& \mathrm{Ma}$ (2010) recommended they consider how students "perceive the importance of their overall experience with mentoring as an indicator of the effectiveness of a mentoring program" (p. 339). These interactions could have occurred in-person, by telephone, by email, or by online medium (e.g., Skype [Version 8.37.0.98; Microsoft, Inc., 2019]). A mentor's ease in using the designated communication method could have affected

Improving Mentoring in Higher Education in Undergraduate Education and Exploring Implications for Online Learning. Camey L. Andersen y Richard E. West.

Página 12 de 25 
mentoring interactions. Additional training may be needed if the mentor had technology concerns that affected the mentoring interactions.

\section{Student Support}

Another important role mentors provided is that of student support. Mentors often provided social and emotional support for undergraduate students who may have been new to college experiences, entering young adulthood, living on their own and away from home and their support network for the first time, and dealing with the increased academic pressures of higher education (Baier et al., 2016; Barbuto et al., 2011; Hu \& Ma, 2010; Letkiewicz et al., 2014). The need for mentor student support increased when the student demographic expanded (Bear \& Jones, 2017; Hernandez et al., 2017; Mondisa \& McComb, 2018). Mentors needed to provide additional support to students in different demographics, including students of different racial and ethnic backgrounds, economically disadvantaged students, and older students beginning school for the first time or returning to school after an absence. In one study, even students who did not want mentor support were positively influenced by it, possibly due to low expectations for mentoring (Cox et al., 2014).

Supportive mentors look for opportunities to build trust with mentees. For example, Bear and Jones (2017) studied undergraduate students' relationships with online advisors and found "a positive relationship between the level of protege trust in a mentor and the protege's satisfaction with the mentoring relationship" (p. 158). Particularly where there are racial, ethnic, cultural, or gender differences, mentors who were willing to acknowledge and discuss these topics with students created more open and honest mentoring relationships where students feel comfortable discussing questions or concerns (Butz et al., 2018; Villaseñor et al., 2013).

The literature showed that mentors need to create a supportive connection with the individual student, regardless of mentoring program format or individual circumstances. Another study reporting the top three mentor activities listed "feeling respected as an individual," was the most frequent mentor activity, followed closely by "being a role model," and "providing empathy for the concerns and feeling of the students" (Castellanos et al., 2016, p. 93). Mentors' support skills are clearly important student concerns but may be more challenging to provide training for or develop and in the expected time frame of both mentors and mentees (Shaffer et al., 2010).

\section{Role Models}

In the literature, mentors served as role models, both formally and informally, for the students they mentored. Simply described, role modeling in mentoring is "everyday habits demonstrated through the example of . . . behavior that [provides] guidance to students" (Healy et al., 2012, p. 89). Most mentoring programs expected some degree of role modeling by mentors for their student proteges (Bear \& Jones, 2017; Bowser et al., 2014; Healy et al., 2012; Poor \& Brown, 2013). How explicitly this expectation is stated or reinforced varied by program. In several studies, effective mentor role models positively affected the how the students viewed mentoring (Bear \& Jones, 2017; Castellanos et al., 2016; Smith-Ruig, 2014). The mentor role model also positively influenced how the student viewed the higher education institution or the sponsoring organization of the mentor (Allen \& Lester, 2012; Castellanos et al., 2016; Liu et al., 2011; Poor \& Brown, 2013). This positive influence can encourage student persistence and retention in education or may point a student towards a company or career where the mentor has affiliation. One study suggested

Improving Mentoring in Higher Education in Undergraduate Education and Exploring Implications for Online Learning. Camey L. Andersen y Richard E. West. 
that undergraduate students may appreciate role modeling and its related impact more than graduate students since they are generally younger, and because of the stage of life and level of academics they are pursuing (Smith-Ruig, 2014).

Having a role model also provides a vision for students of what they can become. In a Washington State University study on women in engineering, having professional volunteer female engineers who had graduated from the program as mentors and role models for students "[provided] a direct role model and example of how a woman can succeed in her field of study" (Poor \& Brown, 2013, p. 426). In multiple studies, mentors who helped students gain a clearer perspective of their academic and professional future fostered a positive mentoring relationship with students (Barbuto et al., 2011; Poor \& Brown, 2013).

\section{Implications for Practice}

In considering implications for practice, the role of mentor could be strengthened in the following ways: First, mentors should establish a personal connection with mentee students as a highest priority (Luckett \& Luckett, 2009). Luckett and Luckett's (2009) analysis concluded, "Most undergraduate first generation students . . . are in the process of developing their personal and social identities. This may explain why the majority of students responded better to those mentors who could offer them recognition, affirmation and some intimacy, as opposed to those who offered only professional expertise" (p. 480). Mentors may need additional training in how to be role models online, since this research is lacking in the literature. Second, mentor roles can be strengthened as mentors better understand who is being advised. With improved feedback from students on the role they want mentors to play, mentors will know who wants prescriptive feedback and who wants developmental feedback (Braun \& Zolfagharian, 2016). Anderson et al. (2014) explain, "Advisors should be equipped to provide either developmental or prescriptive advising based on student needs" (p. 36). Better insights on demographics and cultural needs will also assist mentors in meeting mentoring objectives and fulfilling mentor roles. Mentors can also seek to improve trust with mentees by being direct in discussing racial or ethnic issues (Bear \& Jones, 2017; Butz et al., 2018). Being upfront in addressing protegee background can show understanding and respect and lead to improved communication. As mentors catch the vision of their role as mentor and understand their responsibilities, they will be better able to help students.

\section{Mentoring Programs}

As the literature shows, one of the challenges in defining mentoring is the variety in mentoring programs and how they are applied in higher education settings. Some mentoring programs have an organized structure and recruit students for mentoring assistance. Other mentoring takes place informally or as part of a larger educational benefit within the higher education context. Ambrose and Williamson Ambrose (2013) explained additional differences: "All methods of advising involve two elements: space and time. Students and advisors interact either synchronously (same time) or asynchronously (different time). Similarly, students might engage with their advisors on campus (same place) or online (different place)" (p. 79). These differences in mentoring models result in many different mentoring examples and possibilities.

\section{Types of Mentoring Programs}

Improving Mentoring in Higher Education in Undergraduate Education and Exploring Implications for Online Learning. Camey L. Andersen y Richard E. West. 
Mentoring programs can be classified into structured and unstructured programs. Structured mentoring programs may be focused on general students or around a specific college major, internship or career path, gender, or racial or ethnic group. These programs may have a formal mentoring selection process, specific guidance on how mentors and mentees should interact, and follow up at the end of the program. Structured programs can help lessen concerns for mentors and mentees as new partnerships begin because expectations are established based on the program outline (Ambrose \& Williamson Ambrose, 2013; Halupa \& Henry, 2015). Particularly when there may be racial or cultural differences, these structured programs such as featured in the Dahlvig (2010) study, could facilitate a positive meeting experience and as one study participant described, "force people to get uncomfortable" (p. 39).

In the research, structured programs also provided a standard for mentoring that is useful in working with unknown backgrounds and beliefs of mentors (Martin \& Bok, 2015). One aspect of establishing a mentoring program standard is clearly identifying the roles of the individuals involved in the program, including mentors, students, administrators, and other volunteers (Black \& Taylor, 2018). In a Black and Taylor (2018) study that reviewed 187 higher education mentoring program websites at Texas four-year public colleges and universities, only approximately onethird of programs (37\%) identified these roles. More explanation of responsibilities in a mentoring program can improve the experience for all involved by establishing expectations for program participation and benefits.

The structured mentoring program provides additional benefits to mentors by assisting them in the mentoring process. The program could provide guidelines of how the mentor assists the mentee in their academic or career-planning process. These guidelines may take the form of mentor discussion, interaction, or written communication with students. For example, some programs provided suggestions about setting goals. How the mentor and mentee chose to follow the mentoring program determined the satisfaction of the mentoring relationship. According to Halupa and Henry (2015), in a small study of four mentor teams, "Only one mentee/mentor pair established formal goals; the remainder did not even though this was outlined in the mentor guide all participants received. It is interesting to note the group that established the goals were more satisfied overall with the mentor/mentee relationship" (p. 110). Without formal mentoring goals in place, mentors and mentees may agree to different types of interaction (e.g., in person meetings or online contact) but lack of structure may keep them from consistently following through on mentoring plans (Rees Lewis et al., 2018).

Another study described how "regulation tools," such as a system to read mentee email reports, benefitted mentors:

In interviews, coaches described how reading the stand-reports [a structured report written by students about their daily and weekly goals] helped them gain awareness of team actions. All coaches reported that they regularly (minimum every 2 days) read the emails with the stand-reports . . . . All coaches reported that reviewing stand-reports helped them gain awareness of team behavior and cognition. (Rees Lewis et al., 2018, p. 12)

In this study, prior to the communication regulation, mentors may have not read student messages (Rees Lewis et al., 2018). This research showed that formalizing the mentoring communication process improved mentors' understanding of student issues and their ability to support students. Structured mentoring programs provided confidence to mentors and students of roles and expectations for mentoring relationships.

Improving Mentoring in Higher Education in Undergraduate Education and Exploring Implications for Online Learning. Camey L. Andersen y Richard E. West.

Página 15 de 25 
Unstructured mentoring or mentoring programs provide mentoring services but may be part of a larger collection of student services or may provide more limited mentoring services than a structured mentoring program. Unstructured mentoring could also be mentors self-selected by students to help them academically or professionally and students could benefit from the informality of this process and what it provided (Hernandez et al., 2017). In one study where students met with a financial mentor in an unstructured mentoring program, "the predicted odds of taking more than four years to complete the undergraduate degree is $17 \%$ lower for students who have met with a financial counselor or advisor" (Letkiewicz et al., 2014, p. 365). Without a formal plan, unstructured mentoring programs could require more effort on the part of mentors and students to achieve desired results. Effective mentors become familiar with their designated mentoring program and learn how to use it for the student's benefit.

\section{Mentoring In-person, Online, or Blended}

The literature discussed three platforms for mentoring: in-person, online, and blended. While in-person has been the traditional mentoring approach, with the increase in online communication, there has been a trend towards online and blended mentoring approaches. Even predominantly in-person approaches are still frequently influenced by online contact through email or other electronic communication.

In-person mentoring allows mentors and students to connect in person. Unless otherwise stated, most articles in this review examined a face-to-face mentoring approach (Allen \& Lester, 2012; Braun \& Zolfagharian, 2016; Hernandez et al., 2017; Luckett \& Luckett, 2009; Shaffer et al., 2010). In-person mentoring requires the mentor and mentee to identify a mutually agreeable time and place to visit with each other and a location to meet, and may be limited to school or working hours. Because in-person interaction has been the mentoring standard, the literature generally has not focused on it as a separate method. However, the method highlights particular mentoring skills discovered in studies and manifested in in-person mentoring (Cox et al., 2014; Healy et al., 2012; Hu \& Ma, 2010; Poor \& Brown, 2013). Many of these skills are discussed in the previous section on Role of Mentor. The in-person interaction with internship students provided additional details about how that mentoring that took place in work environments. For internship students, the mentor worked in person with them in connection with their job to help them understand protocol and perspectives of an employment environment (Smith-Ruig, 2014). Other mentors for student interns served in supervision and collaboration roles as they interacted together (Bowser et al., 2014). The characteristics of in-person mentoring are more fully understood when considered in relationship to online and blended mentoring.

Online mentoring allows for mentoring to extend beyond location and time constraints and provides greater access to a variety of mentorship traits and skills. It also provides flexibility for scheduling mentoring opportunities that may not be available with in person mentoring. If a mentor or student is able to provide these mentoring requests for an online mentoring program, there could be greater likelihood for success for the relationship.

Online mentoring articles referenced two scenarios. First was the online interaction between mentors and mentees. Most online mentoring interactions required minimal or no additional cost from mentors and students (Halupa \& Henry, 2015). Online mentoring could occur through email, texting, free web services such as Zoom (Version 3.6.5; Zoom Video Communications, Inc, 2019) or Skype, and document sharing such as Google Docs.

Improving Mentoring in Higher Education in Undergraduate Education and Exploring Implications for Online Learning. Camey L. Andersen y Richard E. West.

Página 16 de 25 
Second, online mentoring referred to organized online mentoring platforms that provided information about mentors and mentees and arguably provided more effective mentoring matches than random selection. These programs could require fees from the higher education organizations, students, or both. In one study of an online mentoring program, "all mentors agreed it was better to do mentor/mentee matches based on a system that actually looks at personal and professional characteristics" (Halupa \& Henry, 2015, p. 111). Other studies also showed a positive effect from using an online tool to match mentor and student characteristics (Martin \& Bok, 2015; Rees Lewis et al., 2015). In another study, mentors were not persuaded of the benefits of the specific online mentoring platform they were using but were in favor of a similar mentoring matching process through another site such as LinkedIn, Skype, or a university-created mentoring program (Halupa \& Henry, 2015).

A blended platform combines both in-person and online mentoring components. In the literature several programs that are defined as online programs are actually blended programs (Rees Lewis et al., 2018; Sanyal \& Rigby, 2017). Ambrose and Williamson Ambrose (2013) argued that the blended format combines the best of all mentoring practices:

[From] the benefits of synchronous, on campus advising - "same time, same place" experiences that enable human connection and spontaneity - while simultaneously taking advantage of the asynchronicity and computer-mediated environment of online advisingor "different time, different place" experiences that afford more opportunities for flexibility and accessibility, thereby leaving out any weaknesses from either method. (p. 79)

With the increase of online education in higher education and as a result of COVID-19, online and blended mentoring has become increasingly prevalent. The most effective mentors will understand the benefits and constraints of each platform and be able to mentor in any of them.

\section{Mentoring Training}

Mentoring programs and mentors' abilities to be effective will be significantly impacted by how training is incorporated into the mentoring program. These literature review articles showed that mentor training is lacking (Bear \& Jones, 2017; Bowser et al., 2014; Kramer-Simpson, 2018). Research also showed that online mentoring training programs in particular lack technology training, and if mentors do not understand or feel competent in the skills they are taught, they may not provide adequate mentoring for students (Ambrose \& Williamson Ambrose, 2013). Thus, mentoring programs need to ensure their mentors feel confident in their technology skills, particularly if they will be doing online mentoring.

For example, for mentors to be most effective, they need training in how to best interact and communicate with students. Mentors need to be trained that from the beginning of the mentoring relationship, they should clearly express goals for students and what they can anticipate accomplishing with the guidance of the mentor and the mentoring program (Mondisa \& McComb, 2018). They also need training on how to personalize the mentoring experience for individual students within that framework of program goals (Gravel, 2012). Mentors need to convey why the mentoring program activities are valuable to student learning. Mentors may need diversity and cultural training to improve understanding of issues facing minority students (Butz et al., 2018; Castellanos et al., 2016; Dahlvig, 2010). Mentors also need training in how to best assist students in career planning (Renn et al., 2014). Empowering students with career-planning skills can give

Improving Mentoring in Higher Education in Undergraduate Education and Exploring Implications for Online Learning. Camey L. Andersen y Richard E. West. 
them confidence that they can find and succeed in future employment. Effective mentors seek out initial and ongoing training to increase their learning and mentoring skills.

\section{Implications for Practice}

This review shows that mentoring programs can be improved by better organization to their structure and format. First, unstructured or less structured mentoring organizations can add more structure to their programs. Mentoring programs can improve contact and website content to provide better online information about mentoring to both students and possible mentor candidates. One study in the review showed that almost 10 percent of mentoring program websites did not provide a method of contact (Black \& Taylor, 2018). Without current information on a website, students may not seek further mentoring help, nor mentors seek additional information about mentoring. Organizations can also better identify program mentoring expectations and goals for both mentors and students and establish better instruments for measuring mentoring progress (Cox et al., 2014; Martin \& Bok, 2015). These goals can be discussed in the first meetings between mentor and mentee and should be incorporated with mentee and mentor goals in the mentoring relationship.

Mentoring programs can also be improved by more evaluation. As mentors and students provide more feedback on the program itself and their mentoring relationships, they invest in the organization and contribute to its long-term success. Creating an evaluation plan to assess student perceptions of advising can improve mentoring services (Anderson et al., 2014). Evaluations will also help mentors and mentees feel valued and let mentoring programs know what areas need improvement (Black \& Taylor, 2018). Evaluation of the program structure can lead to improved mentoring.

\section{Implications for Future Research}

This review shows that more research on mentoring and higher education is needed and is not keeping pace with the increase in students enrolled in higher education institutions, particularly online. More studies are needed on the long-term effects of mentoring and how students benefit after their college graduation (Mondisa \& McComb, 2018). Such studies would encourage institutions to place a higher priority on mentoring programs, as well as businesses who hire their graduates. We need to better understand how much mentoring students need to maximize their academic potential and the best role of mentors in this process. Also, research can study whether students need mentoring for all four years of college or is quality mentoring by mentors the first year or two adequate to set students on the path of persistence and long-term success (Hernandez et al., 2017)? Especially, research is needed into the effectiveness of online mentoring, and whether this type of mentoring can be effective at helping online students find similar success as their inperson peers.

In addition, the literature is significantly lacking in studies on mentor training. What training methods are most beneficial for mentor learning (Martin \& Bok, 2015)? What follow up mentor training is needed to maintain quality mentoring over time? What are the mentor concerns? There is very little provided in the literature on the perspective of mentors.

Additional studies might include: With the increase in online mentors, what additional training do they need? How can mentor technologies impact their ability to mentor online (Gravel,

Improving Mentoring in Higher Education in Undergraduate Education and Exploring Implications for Online Learning. Camey L. Andersen y Richard E. West.

Página 18 de 25 
2012; Sanyal \& Rigby, 2017)? For example, can video technologies allow mentors to establish the relationships with their mentees while permitting online flexibility? Are these video interactions more important at certain times of the mentoring relationships? Can online mentors maintain a strong mentor relationship with mentees over time without in person contact?

These high-interaction mentoring relationships can be expensive for institutions to maintain, however. One intriguing possibility may be to maximize volunteer mentoring to minimize mentoring costs to their organizations (Coles, 2011), but more research is needed on the effectiveness of these volunteer programs. In addition, how can colleges and universities minimize mentor attrition to maximize training benefits? How can mentors best understand and maximize their role as mentors to impact students (Healy et al., 2012)? More research is also needed on online mentoring skills, on how online mentoring differs from traditional mentoring, and what tools online mentors can use to better assist students. An updated comprehensive review of mentoring literature that includes an examination of traditional and online mentoring methods would extend the research of Jacobi (1991), Crisp and Cruz (2009), and Gershenfeld (2014), and would be helpful for mentoring scholars and provide additional insight into effective mentoring.

\section{Conclusion}

Mentors have the opportunity to make a meaningful difference in student lives at a critical learning moment that can change their futures for the better. This research can help those who want to improve their mentoring program and practices, and their mentor skills professionally or personally. This review of mentoring and higher education literature has added to the academic discussion by providing research insights into mentoring while showing gaps in missing information. This literature review shows that effective mentoring occurs as mentors recognize their contribution to long-term student success and the impact of mentoring, understand their role as mentors, and have the benefit of an organized mentoring program design to assist them in their mentoring. The literature analysis showed the impact of mentoring through student retention, student persistence and long-term benefits for students that extend beyond the college experience. The analysis also showed how mentors come to better understand their role as mentors through student interaction, supporting students, and serving as role models. In addition, the review presented characteristics of effective mentoring programs and emphasized the importance of mentor training. More research in all of these areas is needed in academic studies, but research is particularly needed regarding online mentoring, the design of mentoring programs, and mentor training. With the sudden global changes to higher education as a result of COVID-19, effective online mentoring has become more critical than ever before. More students will be participating in online education and need the support that online mentoring can provide, but online mentors need to be able to reach out to them effectively.

Mentoring is a key factor in undergraduate students' potential for academic success (Baier et al., 2016; de Janasz \& Godshalk, 2013). Institutions of higher education can lead the way in providing mentoring services, particularly for first year students and students with underrepresented demographic and cultural backgrounds, but all students can benefit from mentoring. Training mentors in quality mentoring practices for students can improve the academic outcomes higher education desires and can give mentors the tools they need to feel confident in helping students succeed.

Improving Mentoring in Higher Education in Undergraduate Education and Exploring Implications for Online Learning. Camey L. Andersen y Richard E. West.

Página 19 de 25 
Received: January 20, 2020

Accepted: July 13, 2020

Published: September 30, 2020

Andersen, C.L. y West, R.E. (2020). Improving Mentoring in Higher Education in Undergraduate Education and Exploring Implications for Online Learning. RED. Revista Educación a Distancia, 20(64). http://dx.doi.org/10.6018/red.408671

\section{Funding}

This research has not received any specific grant from funding agencies in the public, commercial or non-profit sectors.

\section{References}

Allen, I. H., \& Lester, S. M., Jr. (2012). The impact of a college survival skills course and a success coach on retention and academic performance. Journal of Career and Technical Education, 27(1), 8-14.

Allen, T. D., \& Eby, L. T. (2003). Relationship effectiveness for mentors: Factors associated with learning and quality. Journal of Management, 29(4), 469-86. doi: 10.1016/S01492063(03)00021-7

Ambrose, G. A., \& Williamson Ambrose, L. (2013). The blended advising model: transforming advising with ePortfolios. International Journal of ePortfolio, 3(1), 75-89.

Anderson, W., Motto, J. S., \& Bourdeaux, R. (2014). Getting what they want: Aligning student expectations of advising with perceived advisor behaviors. Mid-Western Educational Researcher, 26(1), 27-51.

Baier, S. T., Markman, B. S., \& Pernice-Duca, F. M. (2016). Intent to persist in college freshmen: The role of self-efficacy and mentorship. Journal of College Student Development, 57(5), 614-619. doi: 10.1353/csd.2016.0056

Bandura, A. (1977). Self-efficacy: Toward a unifying theory of behavioral change. Psychological Review, 84(2), 191-215.

Barbuto, J. E., Story, J. S., Fritz, S. M., \& Schinstock, J. L. (2011). Full range advising: Transforming the advisor-advisee experience. Journal of College Student Development, 52(6), 656-670. doi: 10.1353/csd.2011.0079

Bear, S., \& Jones, G. (2017). Students as protégés: Factors that lead to success. Journal of Management Education, 41(1), 146-168. doi: 10.1177/1052562916658688

Bierema, L. L., \& Merriam, S. B. (2002). E-mentoring: Using computer mediated communication to enhance the mentoring process. Innovative Higher Education, 26(3), 211-227.

Bettinger, E. P., \& Baker, R. B. (2014). The effects of student coaching: An

Improving Mentoring in Higher Education in Undergraduate Education and Exploring Implications for Online Learning. Camey L. Andersen y Richard E. West.

Página 20 de 25 
evaluation of a randomized experiment in student advising. Educational Evaluation and Policy Analysis, 36(1), 3-19. doi: 10.3102/0162373713500523

Black, V. G., \& Taylor, Z. W. (2018). Nobody's talking to the mentees. Mentoring and Tutoring, 26, 606-626. doi: 10.1080/13611267.2018.1561027

Bowser, A., Hux, A., McBride, J., Nichols, C., \& Nichols, J. (2014). The roles of site-based mentors in educational leadership programs. College Student Journal, 48(3), 468-472.

Bradley, R. L., Browne, B. L., \& Kelley, H. M. (2017). Examining the influence of self-efficacy and self-regulation in online learning. College Student Journal, 51(4), 518-530.

Braun, J., \& Zolfagharian, M. (2016). Student participation in academic advising: Propensity, behavior, attribution and satisfaction. Research in Higher Education, 57(8), 968-989. doi: 10.1007/s11162-016-9414-2

Butz, A. R., Spencer, K., Thayer-Hart, N., Cabrera, I. E., \& Byars-Winston, A. (2018). Mentors' motivation to address race/ethnicity in research mentoring relationships. Journal of Diversity in Higher Education, 12(3), 242-254. doi: 10.1037/dhe0000096

Castellanos, J., Gloria, A. M., Besson, D., \& Harvey, L. O. C. (2016). Mentoring matters: Racial ethnic minority undergraduates' cultural fit, mentorship, and college and life satisfaction. Journal of College Reading and Learning, 46(2), 81-98. doi: $10.1080 / 10790195.2015 .1121792$

Coles, A. (2011). The role of mentoring in college access and success. Research to practice brief. Washington, D.C.: Institute for Higher Education Policy.

Cox, C. B., Yang, Y., \& Dicke-Bohmann, A. K. (2014). What do Hispanic students want in a mentor? A model of protégé cultural orientation, mentorship expectations, and performance. Journal of Hispanic Higher Education, 13(4), 359-376. doi: $10.1177 / 1538192714546747$

Crisp, G., \& Cruz, I. (2009). Mentoring college students: A critical review of the literature between 1990 and 2007. Research in Higher Education, 50(6), 525-545. doi: 10.1177/1538192710371982

Dahlvig, J. (2010). Mentoring of African American students at a predominantly white institution (PWI). Christian Higher Education, 9(5), 369-395. doi: 10.1080/15363750903404266

Dawson, P. (2014). Beyond a definition: Toward a framework for designing and specifying mentoring models. Educational Researcher, 43(3), 137-45. doi:10.3102/0013189X14528751

de Janasz, S. C., \& Godshalk, V. M. (2013). The role of e-mentoring in protégés' learning and satisfaction. Group and Organization Management, 38(6), 743-774. doi: $10.1177 / 1059601113511296$

Dumford, A. D., \& Miller, A. L. (2018). Online learning in higher education: exploring advantages and disadvantages for engagement. Journal of Computing in Higher Education, 30(3), 452-465.

Ehrich, L. C., Hansford, B., \& Tennent, L. (2004). Formal mentoring programs in education and other professions: A review of the literature. Educational Administration Quarterly, 40(4), 518-540. doi: 10.1177/0013161X04267118

Improving Mentoring in Higher Education in Undergraduate Education and Exploring Implications for Online Learning. Camey L. Andersen y Richard E. West. Página 21 de 25 
Gaffney, N. A. (Ed.) (1995). A conversation about mentoring: Trends and models. Washington D.C.: Council of Graduate Schools.

Gershenfeld, S. (2014). A review of undergraduate mentoring programs. Review of Educational Research, 84(3), 365-391. doi: 10.3102/0034654313520512

Gillett-Swan, J. (2017). The challenges of online learning: Supporting and engaging the isolated learner. Journal of Learning Design, 10(1), 20-30.

Gravel, C. A. (2012). Student-advisor interaction in undergraduate online degree programs: A factor in student retention. NACADA Journal, 32(2), 56-67.

Halupa, C., \& Henry, M. (2015). Using VineUp to match students with alumni industry mentors in engineering: A pilot study. International Journal of Higher Education, 4(4), 105-112. doi: 10.5430/ijhe.v4n4p105

Hamilton, B. A., \& Scandura, T. A. (2003). E-Mentoring: Implications for organizational learning and development in a wired world. Organizational Dynamics, 31(4), 388-402. doi: 10.1016/S0090-2616(02)00128-6

Healy, M. A., Lancaster, J. M., Liddell, D. L., \& Stewart, D. L. (2012). The role of the campus professional as a moral mentor. New Directions for Student Services, 2012(139), 83-92.

Henry, J., Bruland, H. H., \& Sano-Franchini, J. (2011). Course-embedded mentoring for first-year students: Melding academic subject support with role modeling, psycho-social support, and goal setting. International Journal for the Scholarship of Teaching and Learning, 5(2), 2-22. doi: 10.20429/ijsotl.2011.050216

Hernandez, P. R., Estrada, M., Woodcock, A., \& Schultz, P. W. (2017). Protégé perceptions of high mentorship quality depend on shared values more than on demographic match. Journal of Experimental Education, 85(3), 450-468. doi: $10.1080 / 00220973.2016 .1246405$

Hinds, E. M., \& Shultz, G. V. (2018). Investigation of the factors that influence undergraduate student chemistry course selection. Journal of Chemical Education, 95(6), 913-919. doi: 10.1021/acs.jchemed.7b00833

Hobson, A. J., Ashby, P., Malderez, A., \& Tomlinson, P. D. (2009). Mentoring beginning teachers: What we know and what we don't. Teaching and Teacher Education, 25(1), 207-216. doi: 10.1016/j.tate.2008.09.001

Hu, S., \& Ma, Y. (2010). Mentoring and student persistence in college: A study of the Washington State Achievers Program. Innovative Higher Education, 35(5), 329-341. doi: 10.1007/s10755-010-9147-7

Jacobi, M. (1991). Mentoring and undergraduate academic success: A literature review. Review of Educational Research, 61(4), 505-532.

Jensen, D. (2017). Mentoring in a distributed learning social work program. Journal of Social Work Education, 53(4), 637-650. doi: 10.1080/10437797.2017.1287026

Johnson, W. B. (2015). On being a mentor: A guide for higher education faculty. New York, NY: Routledge.

Kramer-Simpson, E. (2018). Moving from student to professional: Industry mentors

Improving Mentoring in Higher Education in Undergraduate Education and Exploring Implications for Online Learning. Camey L. Andersen y Richard E. West. Página 22 de 25 
and academic internship coordinators supporting intern learning in the workplace.

Journal of Technical Writing and Communication, 48(1), 81-103. doi:

10.1177/0047281616646753

Lenear, P. E. (2007). E-Mentoring Interaction Models. Paper presented at International Research Conference in the Americas of the Academy of Human Resource Development, Indianapolis, IN.

Letkiewicz, J., Lim, H., Heckman, S., Bartholomae, S., Fox, J. J., \& Montalto, C. P. (2014). The path to graduation: Factors predicting on-time graduation rates. Journal of College Student Retention, 16(3), 351-371. doi: 10.2190/CS.16.3.c

Lev, E. L., Kolassa, J., \& Bakken, L. L. (2010). Faculty mentors' and students' perceptions of students' research self-efficacy. Nurse Education Today, 30(2), 169-174. doi:10.1016/j.nedt.2009.07.007

Liu, Y., Xu, J., \& Weitz, B. A. (2011). The role of emotional expression and mentoring in internship learning. Academy of Management Learning \& Education, 10(1), 94-110. doi: 10.5465/amle.10.1.zqr94

Luckett, K., \& Luckett, T. (2009). The development of agency in first generation learners in higher education: A social realist analysis. Teaching in Higher Education, 14(5), 469-481. doi: 10.1080/13562510903186618

Lunsford, L. G. (2011). Psychology of mentoring: The case of talented college students. Journal of Advanced Academics, 22(3), 474-498. doi: 10.1177/1932202X1102200305

Martin, D., \& Bok, S. (2015). Social dominance orientation and mentorship: Mitigating hierarchical preference through work roles or just low expectations? Personnel Review, 44(4), 592-610. doi: 10.1108/PR-08-2013-0141

McClure, J. L. (2017). The impact of advisor outreach on priority registration. College and University, 92(3), 63-67.

Microsoft, Inc. (2019). Skype (8.37.0.98). Retrieved from https://www.skype.com/en/

Mondisa, J.-L., \& McComb, S. A. (2018). The role of social community and individual differences in minority mentoring programs. Mentoring \& Tutoring, 26(1), 91-113. doi: 10.1080/13611267.2018.1445432

Neely, A. R., Cotton, J., \& Neely, A. D. (2017). E-mentoring: A model and review of the literature. AIS Transactions on Human-Computer Interaction, 9(3), 220-242. doi: 10.17705/1 thci.00096

Nora, A., \& Crisp, G. (2007). Mentoring students: Conceptualizing and validating the multidimensions of a support system. Journal of College Student Retention, 9(3), 337-356. doi: 10.2190/CS.9.3.e

Poor, C. J., \& Brown, S. (2013). Increasing retention of women in engineering at WSU: A model for a women's mentoring program. College Student Journal, 47(3), 421-428.

Purcell, K. (2004). Making e-mentoring more effective. American Journal of Health-System Pharmacy, 61(3), 284-286. doi: 10.1093/ajhp/61.3.284

Putsche, L., Storrs, D., Lewis, A. A., \& Haylett, J. (2008). The development of a mentoring program for university undergraduate women. Cambridge Journal of Education, 38(4), 513-528. doi: 10.1080/03057640802482322

Ragins, B. R., \& Kram, K. E. (2007). The handbook of mentoring at work: Theory, research, and

Improving Mentoring in Higher Education in Undergraduate Education and Exploring Implications for Online Learning. Camey L. Andersen y Richard E. West. Página 23 de 25 
practice. Thousand Oaks, CA: Sage Publications.

Rees Lewis, D. G., Easterday, M. W., Harburg, E., Gerber, E. M., \& Riesbeck, C. K. (2018). Overcoming barriers between volunteer professionals advising project-based learning teams with regulation tools: Overcoming advising barriers with regulation tools. British Journal of Educational Technology, 49(3), 354369. doi: 10.1111/bjet.12550

Rees Lewis, D., Harburg, E., Gerber, E., \& Easterday, M. (2015, June). Building support tools to connect novice designers with professional coaches. In Proceedings of the 2015 ACM SIGCHI Conference on Creativity and Cognition (pp. 43-52). Glasgow, UK: ACM Press. doi: 10.1145/2757226.2757248

Renn, R. W., Steinbauer, R., Taylor, R., \& Detwiler, D. (2014). School-to-work transition: Mentor career support and student career planning, job search intentions, and selfdefeating job search behavior. Journal of Vocational Behavior, 85(3), 422-432. doi: 10.1016/j.jvb.2014.09.004

Sanyal, C., \& Rigby, C. (2017). E-mentoring as a HRD intervention: An exploratory action research study within an international professional mentoring scheme. Human Resource Development International, 20(1), 18-36. doi: 10.1080/13678868.2016.1220156

Schultz, P. W., Hernandez, P. R., Woodcock, A., Estrada, M., Chance, R. C., Aguilar, M., \& Serpe, R. T. (2011). Patching the pipeline: Reducing educational disparities in the sciences through minority training programs. Educational Evaluation and Policy Analysis, 33(1), 95-114. doi: 10.3102/0162373710392371

Shaffer, L. S., Zalewski, J. M., \& Leveille, J. (2010). The professionalization of academic advising: Where are we in 2010? NACADA Journal, 30(1), 66-77.

Shandley, T. C. (1989). The use of mentors for leadership development. NASPA Journal, 27(1), 59-66.

Shrestha, C. H., May, S., Edirisingha, P., Burke, L., \& Linsey, T. (2009). From face-to-face to e-mentoring: Does the "e" add any value for mentors? International Journal on Teaching and Learning in Higher Education, 20(2), 116-124.

Shultz, E. L., Colton, G. M., \& Colton, C. (2001). The adventor program: Advisement and mentoring for students of color in higher education. The Journal of Humanistic Counseling, Education and Development, 40(2), 208-218. doi: 10.1002/j.2164490X.2001.tb00118.x

Smith-Ruig, T. (2014). Exploring the links between mentoring and work-integrated learning. Higher Education Research \& Development, 33(4), 769-782. doi: 10.1080/07294360.2013.863837

Tinto, V. (1975). Dropout from higher education: A theoretical synthesis of recent research. Review of Educational Research, 45(1), 89-125.

Tinto, V. (1993). Building community. Liberal Education, 79(4), 16-21.

Villaseñor, M. J., Reyes, M. E., \& Muñoz, I. (2013). Mujerista, mentoring for Chicanas/Latinas in higher education. Journal of College Student Retention, 15(1), 4964. doi: 10.2190/CS.15.1.d

Vygotsky, L. (1978). Interaction between learning and development. Readings on the Development of Children, 23(3), 34-41.

Improving Mentoring in Higher Education in Undergraduate Education and Exploring Implications for Online Learning. Camey L. Andersen y Richard E. West. Página 24 de 25 
Wandler, J. B., \& Imbriale, W. J. (2017). Promoting undergraduate student self-regulation in online learning environments. Online Learning, 21(2), n2. doi: 10.24059/olj.v21i2.881

$\mathrm{Xu}, \mathrm{D} .$, \& Jaggars, S. (2013). Adaptability to online learning: Differences across types of students and academic subject areas. New York, NY: Columbia University, Community College Research Center. doi: 10.7916/D82N59NB

Zelditch, M. (1990, March). Mentor roles. In Proceedings of the 32nd Annual Meeting of the Western Association of Graduate Schools, 11.

Zoom Video Communications, Inc. (2019). Zoom (3.6.5). Retrieved from https://zoom.us

Improving Mentoring in Higher Education in Undergraduate Education and Exploring Implications for Online Learning. Camey L. Andersen y Richard E. West.

Página 25 de 25 